\title{
Quality of routine health data collected by health workers using smartphone at primary health care in Ethiopia
}

Citation for published version (APA):

Medhanyie, A. A., Spigt, M., Yebyo, H., Little, A., Tadesse, K., Dinant, G-J., \& Blanco, R. (2017). Quality of routine health data collected by health workers using smartphone at primary health care in Ethiopia. International Journal of Medical Informatics, 101, 9-14. https://doi.org/10.1016/j.ijmedinf.2017.01.016

Document status and date:

Published: 01/05/2017

DOI:

10.1016/j.jimedinf.2017.01.016

Document Version:

Publisher's PDF, also known as Version of record

\section{Document license:}

Taverne

\section{Please check the document version of this publication:}

- A submitted manuscript is the version of the article upon submission and before peer-review. There can be important differences between the submitted version and the official published version of record.

People interested in the research are advised to contact the author for the final version of the publication, or visit the DOI to the publisher's website.

- The final author version and the galley proof are versions of the publication after peer review.

- The final published version features the final layout of the paper including the volume, issue and page numbers.

Link to publication

\footnotetext{
General rights rights.

- You may freely distribute the URL identifying the publication in the public portal. please follow below link for the End User Agreement:

www.umlib.nl/taverne-license

Take down policy

If you believe that this document breaches copyright please contact us at:

repository@maastrichtuniversity.nl

providing details and we will investigate your claim.
}

Copyright and moral rights for the publications made accessible in the public portal are retained by the authors and/or other copyright owners and it is a condition of accessing publications that users recognise and abide by the legal requirements associated with these

- Users may download and print one copy of any publication from the public portal for the purpose of private study or research.

- You may not further distribute the material or use it for any profit-making activity or commercial gain

If the publication is distributed under the terms of Article $25 \mathrm{fa}$ of the Dutch Copyright Act, indicated by the "Taverne" license above, 


\title{
Quality of routine health data collected by health workers using smartphone at primary health care in Ethiopia
}

\author{
Araya Abrha Medhanyie ${ }^{\mathrm{a}, *}$, Mark Spigt ${ }^{\mathrm{a}, \mathrm{b}, \mathrm{d}}$, Henock Yebyo ${ }^{\mathrm{a}}$, Alex Little ${ }^{\mathrm{e}}$, Kidane Tadesse ${ }^{\mathrm{a}}$, \\ Geert-Jan Dinant ${ }^{\mathrm{b}}$, Roman Blanco ${ }^{\mathrm{c}, \mathrm{d}}$ \\ a School of Public Health, College of Health Sciences, Mekelle University, P.O. Box 1871, Mekelle, Ethiopia \\ b CAPHRI, Department of Family Medicine, CAPHRI, School for Public Health and Primary Care, Maastricht University, PO Box 616, 6200 MD Maastricht, \\ Netherlands \\ ${ }^{c}$ Department of Surgery, School of Medicine, University of Alcala, 28871 Alcala de Henares, Madrid, Spain \\ ${ }^{d}$ General Practice Research Unit, Department of Community Medicine, The Arctic University of Norway, Tromsø, Norway \\ e Digital Campus, Winchester, 21 North Drive, Littletown, Winchester S022 6QA, England, UK
}

\section{A R T I C L E I N F O}

\section{Article history:}

Received 18 January 2016

Received in revised form

14 December 2016

Accepted 22 January 2017

\section{Keywords:}

Data quality

Primary health care

Maternal health care

mHealth

Electronic forms

Smartphones

\begin{abstract}
A B S T R A C T
Background: Mobile phone based applications are considered by many as potentially useful for addressing challenges and improving the quality of data collection in developing countries. Yet very little evidence is available supporting or refuting the potential and widely perceived benefits on the use of electronic forms on smartphones for routine patient data collection by health workers at primary health care facilities. Methods: A facility based cross sectional study using a structured paper checklist was prepared to assess the completeness and accuracy of 408 electronic records completed and submitted to a central database server using electronic forms on smartphones by 25 health workers. The 408 electronic records were selected randomly out of a total of 1772 maternal health records submitted by the health workers to the central database over a period of six months. Descriptive frequencies and percentages of data completeness and error rates were calculated.

Results: When compared to paper records, the use of electronic forms significantly improved data completeness by 209 (8\%) entries. Of a total 2622 entries checked for completeness, 2602 (99.2\%) electronic record entries were complete, while 2393 (91.3\%) paper record entries were complete. A very small percentage of error rates, which was easily identifiable, occurred in both electronic and paper forms although the error rate in the electronic records was more than double that of paper records (2.8\% vs. $1.1 \%)$. More than half of entry errors in the electronic records related to entering a text value.

Conclusions: With minimal training, supervision, and no incentives, health care workers were able to use electronic forms for patient assessment and routine data collection appropriately and accurately with a very small error rate. Minimising the number of questions requiring text responses in electronic forms would be helpful in minimizing data errors.
\end{abstract}

(c) 2017 Elsevier B.V. All rights reserved.

\section{Introduction}

Safe clinical care requires quality patient data and documentation. Collecting good and quality patient data at the point of care has also added benefits for research and health services monitor-

\footnotetext{
* Corresponding author.

E-mail addresses: arayaabrha@yahoo.com (A.A. Medhanyie), m.spigt@maastrichtuniversity.nl (M. Spigt), henokyebyo@yahoo.com (H. Yebyo), alex@alexlittle.net (A. Little), kiducs98@yahoo.com (K. Tadesse), geertjan.dinant@maastrichtuniversity.nl (G.-J. Dinant), roman.blanco@uah.es (R. Blanco).
}

ing and evaluation. Poor quality of data has been shown to result in poor quality of health care services and decision-making [1-4].

One potential avenue currently gaining popularity and considered by many across the globe to address the needs and challenges of data collection and health information systems is the use of mobile technology based solutions [4-6]. The World health Organization (WHO) defines Mobile Health, commonly known as mHealth as "medical and public health practice supported by mobile devices, such as mobile phones, patient monitoring devices, personal digital assistants (PDAs), and other wireless devices". mHealth applications and programs make use of several aspects of mobile technology such as text messaging, voice and video services and internet connection [6]. 
Frameworks and white papers on mHealth for developing countries have highlighted that new generations of smartphones could potentially be useful for population and patient based data collection. The fact that smartphones are portable, have internet access and can run third party applications make them potentially useful and preferable to handheld or desktop computers for population and patient based data collection in developing countries. Using the internet functionality of smartphones, instant transfer of realtime data collected using electronic forms on smartphones from remote areas to a central database server can be achieved. In addition to data collection and transfer, well-designed electronic forms on smartphones may also serve higher purposes such as assisting and guiding health workers with limited training through the diagnostic process by helping them conduct step-by-step assessments. This multi-functionality of smartphones, together with the rapid and widespread penetration of mobile phones in developing countries over the past decade, led to the expectation that electronic forms on smartphones can replace paper forms and thereby improve the quality of health data and patient care [4-8].

Despite this high expectation and the presence of several mHealth initiatives, the lack of sound evidence underpinning the potential benefits of electronic forms in developing countries is striking. Many previous mHealth studies dealt with the use of short message service (SMS) and were conducted in developed countries [8-10]. There is virtually no evidence on the use of electronic forms on smartphones by health workers for routine collection of patient data at primary health care facilities in resource-poor settings. The very few studies that employed electronic forms on mobile phones were mainly tested or used for one-time surveys or surveillance purposes [11-13]. A study conducted in India which evaluated the accuracy of data collection on mobile phones found error rates of $4.5 \%$ for SMS, $4.2 \%$ for electronic forms and $0.45 \%$ for voice interface. These results caused the authors of the study to migrate from their primary intention on using electronic forms to voice interface [12]. Another study conducted in South Africa on the use of mobile phones as data collection tool for a household survey suggested that the conventional paper, and in-person data collection may be preferable over mobile phone interfaces in the case of longer interactions, such as long-form surveys or complex diagnoses [13]. Thus, the use of electronic forms for routine collection of critical health data by health workers in resource-poor settings is still questionable. Missing or duplicated and inconsistent data collected through electronic forms, sent and stored in a central database may render data management and patient care problematic $[1,2,12]$.

In this regard, our study compared the completeness and accuracy of patient data collected using electronic forms on smartphones to that collected by paper forms, by 25 health workers over a period of six months in the Tigray region of Ethiopia. The completeness and accuracy was assessed by matching an electronic record with its respective paper record of the same patient completed by the same health worker.

\section{Methods}

\subsection{Ethical consideration}

This study was approved by the health research and ethics review committee of the College of Health Sciences of Mekelle University. Written consent for participation was obtained for each health worker. The health workers were informed about their right to withdraw from the study at any time. Although the health workers were not informed about the comparison of data quality evaluation at the beginning of the study to avoid unnecessary bias and they had been using the electronic forms as part of their routine work, additional consent from each health worker was sought at the end of the six months to participate in the evaluation of the data quality. Comparison of completeness and entry error rates for each record was done in the presence of the health worker who completed the record.

\subsection{Study setting}

This study was conducted in primary health care setting and based in the context of maternal health care. The Ethiopian primary health care unit is the lowest and frontline level of the health care delivery system. A primary health care unit (PHCU) is composed of a health center and five health posts. A health center is staffed by midlevel health professionals who have diploma and degree level training such as midwives and nurses. On average a health center provides health care for a population of 25,000 people. It supervises and supports five satellite health posts. On average, a health post serves for a population of 5000 people and it is staffed by two health extension workers (HEWs). HEWs are community health workers who are high school complete and took one year training. They educate and provide basic health services such as family planning, antenatal care, delivery and postnatal care.

The study employed midwives and health extension workers (HEWs) who are primarily responsible for maternal health services provision at a primary health care unit in Ethiopia.

\subsection{Participants and study period}

A comparative cross sectional study was conducted, to compare data collected by paper form and electronically collected data from maternal follow up.

In this study, a total of four health centers and nine health posts from two districts: Kilte Awlaelo and Hintalo Wajerat of the Tigray region, Ethiopia were included. All midwives (10) and HEWs (15) who had been working in the selected health facilities participated in this data quality assessment.

By October 2012, the health workers actually started to use the electronic forms and actively submit patient records to our central server using the electronic forms and smartphones. Hence for this study on data quality of electronic forms, we considered the activities of the health workers and records submitted over the six month period from October 2012 to March 2013. Details of the technical development and contents of the mHealth application and electronic forms evaluated for data quality in this study are presented in another published article [14].

\subsection{Data collection and sampling technique}

Prior to the actual use of the electronic forms for patient based data collection and assessment, the health workers received practical training on the use of the smartphone and electronic forms by the research team. Health workers were trained and informed to complete the electronic forms on smartphones in addition to existing paper forms as part of their routine work during clinical encounters. They were instructed to fill out the electronic forms in the presence of the patient. There were no incentives or penalties set for health workers whether or not they used the electronic forms and entered data appropriately and accurately. They were free to decide what best suited their individual work practice in terms of which forms to complete first (paper or electronic forms).

A total of 408 electronic records were randomly selected out of a total of 1772 maternal health care records submitted over the six months period. Of these selected records, nine $(2.2 \%)$ had a duplicated record in our database. These duplicated records were cleared in consultation with health workers before we began crosschecking with their respective paper records. Besides, we were able to trace and match 375 (91.9\%) corresponding paper records. Of 
Table 1

Selected variables and questions for comparison.

\begin{tabular}{lll}
\hline Selected variable & Type of variable & Form \\
\hline Date of visit & Numeric & ANC, ANC lab test, Delivery, PNC \\
Patient ID & Numeric & ANC, ANC lab test, Delivery, PNC \\
Patient name & & ANC, ANC lab test, Delivery, PNC \\
Age & Numeric & ANC, ANC lab test, Delivery, PNC \\
Last Menstrual Period (LMP) & Numeric & ANC \\
Systolic Blood Pressure (SBP) & Numeric & ANC, Delivery, PNC \\
Vaginal Bleeding & Yes/No & ANC and Delivery \\
Body Temperature & Option & Delivery and PNC \\
New born birth weight & Numeric & Delivery and PNC \\
Haemoglobin level & Numeric & ANC lab test \\
\hline
\end{tabular}

$\mathrm{ANC}=$ Antenatal care, $\mathrm{PNC}=$ Postnatal care.

the 375 electronic records for which we traced their respective paper records, 225 (60\%) were Antenatal care (ANC), 73 (19.5\%) were delivery, 39 (10.4\%) were Postnatal care (PNC) and 38 (10.1\%) were ANC lab tests. Thus, in the end, 375 individual patient records were compared across a total of 2622 data points.

Over the six months, the number of electronic patient records submitted by each health worker varied from zero to 372 . Two did not submit any record at all, eight had completed and submitted between three and twenty while the rest 15 submitted more than 20 records. With regards to the distribution of the records submitted by the profession of health worker or type of health facility, almost three quarters of the

records were submitted by midwives (i.e. from health centers), while the remaining quarter of records were submitted by HEWs (i.e. from health posts).

We ensured that each health worker who submitted at least three electronic records was represented in the sample records selected for comparison. To do this, we selected 20 records from each health worker who submitted more than 20 records, while we included all records submitted by a health worker in the sample if he/she submitted less than 20 records during the study period.

To select 20 records from those health workers who submitted more than 20 during the period of the study, we prepared a sampling frame (list of records submitted) by each health worker based on the date of submission and used systematic random sampling to select the required sample records.

We prepared a structured paper checklist of 10 selected questions for the comparison of completeness and accuracy of entries in electronic and their respective paper records. We selected questions that were crucial for the patient recording system or questions that were important components of maternal health care services. When we selected these questions, we aimed at ensuring a mix of different data types (text, numeric, multiple options and yes/no questions) (Table 1 ).

Comparison of record entries was conducted at the end of the study by members of the research team (AAM and KT) who are fluent speakers of the local language, Tigrinya; and took place at the respective health facility in the presence of the health worker who submitted the record.

\subsection{Data analysis}

We employed descriptive statistics and described data completeness and error rates in terms of frequencies and percentages. Data completeness and error rates in electronic and paper records were analysed in terms of the number of incomplete and incorrect entries. Comparison of data completeness was conducted for all selected variables for comparison while error rates were calculated and compared only for five of the variables: Patient name, Systolic Blood pressure (SBP), age, newborn birth weight and haemoglobin level. We did not compare the entry error rates of the other five vari-
Table 2

Socio- demographic characteristic of study participants $(\mathrm{N}=25)$.

\begin{tabular}{ll}
\hline Characteristics & Frequency $(\%)$ \\
\hline Sex & $24(96)$ \\
Female & $1(4)$ \\
Male & \\
Age & $18(72)$ \\
30 or below & $7(28)$ \\
31 or above & \\
Marital status & $16(64)$ \\
Married & $9(36)$ \\
Single & \\
Profession & $15(60)$ \\
HEW & $10(40)$ \\
Midwife & \\
Work experience & $8(32)$ \\
3 years or less & $17(68)$ \\
4 years or more & \\
District & $12(48)$ \\
Hintalowajerat & $13(52)$ \\
Kilteawelaelo & \\
\end{tabular}

ables. These variables are date of visit, patient ID, Last Menstrual Period (LMP), Vaginal bleeding, and Body Temperature. Comparison of entry error rates for these five variables was impossible because some of them such as patient ID were difficult to have an operationally defined standard to claim an entry is a possible error or not while others such as presence of vaginal bleeding were a yes/no or option questions in the electronic/paper forms. We operationally defined an 'error' in the patient name if the name had a spelling error based on the investigator's judgment. An entry in age, SBP, newborn birth weight and haemoglobin level was considered false if the value entered was out of the acceptable rage. We operationally set acceptable ranges for age (15-49 years), SBP (30-200 $\mathrm{mmHg})$, newborn birth weight $(1-5 \mathrm{~kg}$ ) and haemoglobin level (3-20 gm\%). When the actual entry in electronic form and its respective paper form was within the acceptable range but differed, we accepted it as correct entry as we did not have a means to prove whether the difference was because of entry or the measurements were taken at different times.

\section{Results}

\subsection{Socio-demographic characteristics of study participants}

The mean age of the 25 health workers was 31 ( $S D=7$ years). Fifteen $(60 \%)$ of the participants were HEWs while 10 (40\%) were midwives. All health workers except one were female. Seventeen (68\%) of the health workers had 4 or more years of working experience. Thirteen (52\%) of the health workers were working in Kilte Awlaelo district; the remaining $12(48 \%)$ in Hintalo Wajerat district. All health workers had mobile phones prior to enrollment in our study, though none had Android (Google Inc., Mountain View, CA, USA) as an operating system, touch screen interface or local language scripts enabled. Only $3(12 \%)$ of the health workers had ever taken training on basic computer skills though practice did not continue thereafter (Table 2).

\subsection{Data completeness}

When compared against corresponding paper records, the overall completeness of data entries for cross-checked variables was higher in 209 (8\%) entries of electronic records (OR, 12.45, CI 7.86-19.73) (Table 3). Completeness of entries regarding measurements of body temperature, newborn birth weight, and systolic 
Table 3

Data completeness of electronic and paper records for selected variables.

\begin{tabular}{|c|c|c|c|}
\hline Variable/question ( $\mathrm{N}=$ total) & $\begin{array}{l}\text { Completeness on } \\
\text { electronic form (number/\%) }\end{array}$ & $\begin{array}{l}\text { Completeness on paper } \\
\text { form (number/\%) }\end{array}$ & $\begin{array}{l}\text { Difference in completeness } \\
\text { (electronic-paper) } \\
\text { (number/\%) }\end{array}$ \\
\hline Date of visit $(\mathrm{N}=375)$ & $375(100.0)$ & $325(86.7)$ & $50(13.3)$ \\
\hline Patient ID $(\mathrm{N}=375)$ & $375(100.0)$ & $375(100.0)$ & $0(0.0)$ \\
\hline Patient name $(\mathrm{N}=375)$ & $375(100.0)$ & $375(100.0)$ & $0(0.0)$ \\
\hline Patient age $(\mathrm{N}=375)$ & $375(100.0)$ & $375(100.0)$ & $0(0.0)$ \\
\hline Last menstrual period (LMP) $(\mathrm{N}=225)$ & $225(100.0)$ & $204(90.7)$ & $21(9.3)$ \\
\hline Systolic blood pressure (SBP) $(\mathrm{N}=337)$ & $329(97.6)$ & $270(80.1)$ & $59(17.5)$ \\
\hline Vaginal bleeding $(\mathrm{N}=298)$ & $298(100.0)$ & $291(97.7)$ & $7(2.3)$ \\
\hline Body temperature $(\mathrm{N}=112)$ & $112(100.0)$ & $63(56.2)$ & $49(43.8)$ \\
\hline Newborn birth weight $(\mathrm{N}=112)$ & $100(89.3)$ & $77(68.8)$ & $23(20.5)$ \\
\hline Haemoglobin level $(\mathrm{N}=38)$ & $38(100.0)$ & $38(100.0)$ & $0(0.0)$ \\
\hline Total number completed entries (2622) & $2602(99.2)$ & 2393(91.3) & $209(7.9)$ \\
\hline
\end{tabular}

blood pressure in electronic records were found even higher by 49 (43.8\%), 23 (20.5\%), and 59 (17.5\%) entries respectively.

\subsection{Reasons for incomplete entries}

The reasons for the incompleteness of entries in paper records were mainly due to the lack of standard paper forms, in particular, at health posts. Health workers did not enter values of some variables because these were not present in their paper forms. Of the 229 non-entries, $178(77.7 \%)$ were missed because there was no space in the paper forms for the variables. This problem was not present across all health facilities. Only 51 (22.3\%) of the incomplete entries were actually missing values in the paper forms. There was a space in the paper forms for recording values of the variables or measurements which was not used by health workers. The $20(0.8 \%)$ missing entries in the electronic forms regarded measurements of low birth weight and SBP. These variables were required questions, but health workers entered zero when they did not take the actual value in order to proceed to the next question. We considered these zero values as incomplete data.

\subsection{Data accuracy and error rates}

Of the total 2308 entries checked for similarity in the electronic records with their respective entries in paper records, we found 2033 (88.1\%) entries to be identical (Table 4). Although we found a very small percentage of error in both electronic and paper records, the error rate was higher in the electronic records when compared to paper records (2.8\% vs $1.1 \%$ ) (OR, $2.4 \mathrm{CI} 2.4-4.8$ ). All errors were very easy to identify and correct.

When we looked for completeness and accuracy of entry for patient name, we also checked the language used by the health workers. We found 248 (66.1\%) of the entries for patient name in the electronic records were in the Tigrinya language and the remaining 127 (33.9\%) entries in English. Similarly, in the paper records, 241 (64.3\%) entries were in Tigrinya and the remaining 134 (35.75) in English.

\subsection{Reasons for non-identical entries and error rates}

Of the total 274 non-identical entries, more than one third (106, $38.7 \%$ ) pertained to differences in the date of visit. This was mainly due to the reason that some health workers had completed the electronic records, in particular delivery records, one day after completing the paper forms. Some found it difficult and timeconsuming to interview a woman who just gave birth with both paper and electronic forms, while others had problems with date and time setting of their smartphones, thus the dates of visit in the electronic forms were different from the dates of visit in their respective paper records. The differences in measurements such as SBP were real, due to the differences in times of measurement.

Of the total 41 errors identified, almost half $(23,56 \%)$ were errors in spelling from recording patient name in the electronic forms using the smartphone's keyboard. Errors regarding entries of measurements of SBP, birth weight and haemoglobin were typographical problems, which included forgetting to enter a zero at the end of the value, for example entering 12 when the correct value was 120; adding an unnecessary zero at the end of the value, for example writing 1000 when the correct value was 100; and forgetting decimal points, for example entering 133 when the correct value was 13.3

\section{Discussion}

Mobile phone based solutions such as the use of electronic forms on smartphones are considered as potentially useful for improving quality of data collection in developing countries [5-7]. However, some literature argues it is still too early to use this technology for critical and routine health data collection in resource-poor settings with weak health care infrastructure $[8,12,13]$. These studies suggest the use of SMS or voice interfaces instead of electronic forms. Amid this debate, our study enrolled health workers at primary health care settings in Ethiopia to use electronic forms for routine patient based data collection and found encouraging results.

When compared to paper records, the use of electronic forms significantly improved data completeness in $8 \%$ of entries. A very small error rate occurred in both electronic and paper forms, although the error rate in the electronic records was higher than in the paper records (2.8\% vs. $1.1 \%$ ). Many instances of incompleteness and error in both types of forms seemed to arise from problems related to lack of standardized paper-based documentation or unavailability of equipment to record relevant measures.

Although the overall completeness of electronic records was $8 \%$ higher than that of the paper records, for some variables this percentage was even greater. For instance, the completeness of entries in the electronic forms was $43.8 \%$ higher for measurements of body temperature, $20.5 \%$ higher for newborn birth weight, and $17.5 \%$ higher for SBP, than their corresponding paper forms. This is mainly due to the functionality of electronic forms in which questions require the input of a response or value for the form to be accepted. However, from this study we learned that health workers who did not have the necessary functional apparatus such as a thermometer, for measuring body temperature, had been discouraged to use electronic forms and found it difficult to enter a value and proceed to the next question. Hence, when introducing electronic forms for routine patient based data collection, it would be crucial to consider such challenges. Either the electronic form has to be designed in a way to work smoothly with such challenges or the necessary equipment should be made available to health workers. 
Table 4

Data accuracy and error rates of electronic and paper records.

\begin{tabular}{|c|c|c|c|}
\hline Variable/question $(\mathrm{N}=$ total $)$ & $\begin{array}{l}\text { Identical entry between } \\
\text { electronic and paper } \\
\text { records (number/\%) }\end{array}$ & $\begin{array}{l}\text { Confirmed error in } \\
\text { electronic records } \\
\text { (number/\%) }\end{array}$ & $\begin{array}{l}\text { Confirmed error in } \\
\text { paper records } \\
\text { (number/\%) }\end{array}$ \\
\hline Date of visit $(\mathrm{N}=325)$ & $219(67.4)$ & ${ }^{\mathrm{b}} \mathrm{NA}$ & NA \\
\hline Patient ID $(\mathrm{N}=375)$ & $375(100)$ & NA & NA \\
\hline Patient name $(\mathrm{N}=290)^{\mathrm{a}}$ & $264(91.0)$ & $23(7.9)$ & $4(1.4)$ \\
\hline Patient age $(\mathrm{N}=375)$ & $349(93.1)$ & $0(0.0)$ & $1(0.27)$ \\
\hline Last menstrual period (LMP) $(\mathrm{N}=204)$ & $174(85.3)$ & NA & NA \\
\hline Systolic blood pressure (SBP) $(\mathrm{N}=270)$ & $228(84.4)$ & $1(0.37)$ & $2(0.74)$ \\
\hline Vaginal bleeding $(\mathrm{N}=291)$ & $287(98.6)$ & NA & NA \\
\hline Body temperature $(\mathrm{N}=63)$ & $52(82.5)$ & NA & NA \\
\hline Newborn birth weight $(\mathrm{N}=77)$ & $51(66.2)$ & $3(3.9)$ & $5(6.5)$ \\
\hline Haemoglobin level $(\mathrm{N}=38)$ & $35(92.1)$ & $2(5.3)$ & $0(0.0)$ \\
\hline \multirow[t]{2}{*}{ Total number of completed entries checked for similarity (2308) } & $2034(88.1)$ & $29(2.8)$ & $12(1.1)$ \\
\hline & & ${ }^{c} \mathrm{D}=1050$ & $\mathrm{D}=1050$ \\
\hline
\end{tabular}

We found a very small error rate in using electronic forms $(2.8 \%)$ which was less than the error rates (4.2\%) observed in a study by Patnaik $S$ et al. [12]. This decline in error rate may be in some way related to the generation of technology in use. That is we used better smarpthone technology compared to the Patnaik S et al. study which was conducted in 2009. The difference could be also because of the difference in content of the training given, definition and measuring entry error rates, and duration of the study. Our study was conducted for six months while Patnaik $\mathrm{S}$ et al. study was conducted for a month. This might suggest that entry error rates might decline when health workers are exposed to electronic forms for a longer and adequate time.

For all variables checked for accuracy, we found the error rate in electronic records was higher than the error rate in paper records, though still it was small. However, if we were to exclude the errors regarding spelling of patient names, the error rate would be lower in electronic records by two entries when compared to the errors in paper records. The high error of writing names in text might be attributed to the health workers' low proficiency in English and the Ge'ez keyboard we used. Studies and frameworks on mHealth for health workers showed that those workers in developing counties where English is not their native language have a low proficiency in English and the language barrier is frequently mentioned as a challenge for introducing mHealth applications $[5,8,14]$. The Ge'ez or Tigrinya keyboard we used in this study might also have contributed to these errors in entering a text value. Unlike English, the Tigrinya alphabet has more than 33 letters and each letter has seven sounds or characters. Thus, when a health worker had to type the seventh sound of a given letter using the Ge'ez keyboard we installed on the smartphones, the health worker had to type seven times. Doing this may not only cost time but also incur error. Hence, when possible, we recommend other initiatives to look for a user friendly Ge'ez keyboard, which does not require tapping two or more times to write a sound of a letter. Most important, to minimize errors in using electronic forms, questions that require a text response should be used minimally.

Our comparison of data quality and cross-checking for completeness and accuracy of electronic records with their respective paper records gave us an opportunity to identify problems in the existing paper recording system. We observed that few health facilities, in particular health posts, had well-prepared and printed paper forms. Thus, health workers at these health posts were obliged to prepare forms on their exercise book by themselves. This led to self-prepared forms which lacked important variables. Moreover, we observed the available printed paper forms across primary health facilities which were distributed by the health bureau but still noticed a variation between facilities. Such problems may be easily solved by introducing electronic forms into the system. Nevertheless, until a large scale transition from paper forms to electronic forms can be realized, we recommend the Ethiopian Federal Ministry of Health (FMOH) and respective regional health bureaus to standardize the existing paper forms across primary health care facilities.

In this study we compared the data completeness and accuracy of an electronic record with its respective paper record where interviews and entries of values and responses of a patient into both records were made by the same health worker. We did not have any means to check whether electronic records were simply copied from their respective paper records after the patient had left a health facility. This might lead to the assumption that comparison of data quality would have been much stronger had we compared two separate groups: health workers who used only electronic forms versus health workers who used paper forms. However, our comparison of the two types of records showed $67.4 \%$ had an identical date of visit, and the electronic forms had additional questions not present in the paper forms, which were completed by health workers. Therefore, the chance that a health worker could complete an electronic form after a patient had left the health facility by copying from the paper record is deemed very minimal and insignificant to affect the findings of this study.

This study gives a glimpse of the data completeness and entry error rates of electronic and paper records completed by a small number of primary health care workers in Ethiopia. Measurements of completeness and entry error rates were made by operationally defined standards or cut off points as we could not get recommended gold standards or cut off points. Besides, we could not find a study or guideline that recommends the minimum allowable entry error rate and percentage of data incompleteness in collecting routine health data. This made decision making on when to use routine data collected by health workers using electronic and paper records for research and clinical care difficult. Hence, entry error rates reported in this study might be overestimated or underestimated as we did not compare them with a recommended gold standard. Hence, we recommend further works in developing scientific and standard methods of measuring data completeness and entry error rates of routine health data collected though paper, electronic and other possible means in developing countries.

\section{Conclusion}

Using well-designed electronic forms significantly improved data completeness by $8 \%$ when compared to paper records. With minimal training and supervision, and without any incentives and penalties, primary health care workers proved they were able to 


\section{Summary points}

What was already known?

- Mobile phone based application are considered by many as potentially useful for data collection in particular voice and SMS based application.

- Electronic forms on mobile phones were mainly tested and used for one-time survey or surveillance purposes.

What this study has added?

- Electronic forms significantly improved the completeness of routine patient data collection.

- Health workers in Ethiopia were able to use electronic forms for routine patient data collection with a very small error rate.

- Minimizing the number of questions requiring text responses in electronic forms would be helpful in minimizing data errors.

- Many instances of incompleteness and error in electronic forms seemed to arise from problems related with the health system rather than the health workers themselves.

- A friendly and easy -to-use keyboard would be helpful to minimize data errors when using electronic forms on smartphone.

use electronic forms for patient assessment and data collection appropriately and accurately with a very small margin of error. Given that over $50 \%$ of errors in using electronic records pertained to entering text values, and taking health workers' language difficulties into consideration, we recommend other similar initiatives to minimise the of use questions which require text responses in electronic forms. A friendly and easy-to-use keyboard would also be helpful to minimize data errors when using electronic forms on smartphones.

\section{Authors' contributions}

A.A.M. contributed to the design, data collection, analysis, and write-up. HY contributed to the design, data analysis, and write up. KT contributed to the design, data collection, analysis, and write up. MS, AL, GJD, and RB contributed to the design and write up. All authors read and approved the final manuscript.

\section{Funding}

This study was made possible through primary funding provided by Mekelle University (Ethiopia) (http://www.mu.edu.et). AECID (http://www.aecid.es), Alcala University (http://www.uah. es), Maastricht University (http://www.maastrichtuniversity.nl/) and Venture Strategies Innovations (http://vsinnovations.org) also gave additional funding. Software development was supported by Digital Campus Ltd (http://digital-campus.org/), a UK-based not for Profit Company. The funders had no role in study design, data collection and analysis, decision to publish, or preparation of the manuscript.

\section{Conflict of interests}

The authors have declared that they have no conflict of interests.

\section{Acknowledgements}

We are grateful to all health extension workers, midwives, and supervisors who took part in the study. The unreserved support from the Tigray Regional Health Bureau, Kilte Awlaelo and Hintalo Wajerat district health offices was crucial for the success of the study. We thank Samson Yohannes who provided us technical support during the data analysis. We also like to extend our gratitude to Stefanie Suzanne Portelli for her support in language editing and proofreading of this manuscript.

\section{References}

[1] M. Greiver, J. Barnsley, R.H. Glazier, B.J. Harvey, R. Moineddin, Measuring data reliability for preventive services in electronic medical records, BMC Health Serv. Res. 12 (2012) 116.

[2] K. Thriemer, B. Ley, S.M. Ame, M.K. Puri, R. Hashim, N.Y. Chang, L.A. Salim, R.L. Ochiai, T.F. Wierzba, J.D. Clemens, Replacing paper data collection forms with electronic data entry in the field: findings from a study of community-acquired bloodstream infections in Pemba, Zanzibar, BMC Res. Notes 5 (2012) 113.

[3] P.N. Mechael, The case for mHealth in developing countries Innovations, Technology, Governance, Globalization 4 (2009) 103-118.

[4] Vital Wave Consulting, mHealth for Development: the Opportunity of Mobile Technology for Healthcare in the Developing World, UN Foundation-Vodafone Foundation Partnership, 2009.

[5] Earth Institute, Barriers and Gaps Affecting mHealth in Low and Middle Income Countries: A Policy White Paper, mHealth Alliance, Washington, DC, 2010.

[6] World Health Organization, mHealth: New Horizons for Health Through Mobile Technologies, Global Observatory for eHealth Series, WHO, Geneva, 2011.

[7] Vital Wave Consulting, mHealth in Ethiopia: Strategies for a New Framework. mHealth Ethiopia Report, Vital Wave Consulting, 2011.

[8] C. Marshall, D. Lewis, M. Whittaker, mHealth technologies in developing countries: a feasibility assessment and a proposed framework, in: Working Paper, The University of Queensland, 2013.

[9] A.S. Mosa, I. Yoo, L. Sheets, A systematic review of healthcare applications for smartphones, BMC Med. Inform. Decis. Mak. 12 (2012) 67.

[10] H. Cole-Lewis, T. Kershaw, Text messaging as a tool for behavior change in disease prevention and management, Epidemiol. Rev. 32 (2010) 56-69.

[11] Z.A. Rajput, S. Mbugua, D. Amadi, V. Chepngeno, J.J. Saleem, Y. Anokwa, C. Hartung, G. Borriello, B.W. Mamlin, S.K. Ndege, Evaluation of an Android based mHealth system for population surveillance in developing countries, J. Am. Med. Inform. Assoc. 19 (2012) 655-659.

[12] S. Patnaik, E. Brunskill, W. Thies, Evaluating the accuracy of data collection on mobile phones: a study of forms, SMS, and voice, Proc IEEE/ACM Int'l Conf Information and Comm Technologies and Development (ICTD) (2009).

[13] M. Tomlinson, W. Solomon, Y. Singh, T. Doherty, M. Chopra, P. Ijumba, A.C. Tsai, D. Jackson, The use of mobile phones as a data collection tool: a report from a household survey in South Africa, BMC Med. Inform. Decis. Mak. 9 (2009) 51.

[14] A. Little, A. Medhanyie, H. Yebyo, M. Spigt, G.J. Dinant, R. Blanco, Meeting community health worker needs for maternal health care service delivery using appropriate mobile technologies in ethiopia, PLoS One 8 (2013) e77563. 